\title{
METODOLOGIA DE PESQUISA NA REALIZAÇÃO DA BIOGRAFIA DE ARTISTAS BRASILEIROS OITOCENTISTAS: CRÍTICAS E PROPOSTAS
}

\author{
Camila Dazzi ${ }^{1}$
}

\section{Resumo}

A presente comunicação tem como objetivo propor uma reflexão crítica a respeito das metodologias utilizadas na produção historiográfica da arte, contemplando uma questão que, apesar de sua grande importância, tem sido muito pouco pensada pelos estudiosos da arte brasileira: a ausência de métodos de pesquisa criteriosos na realização da biografia de artistas brasileiros atuantes no século XIX. Boa parte da fortuna crítica de caráter enciclopédico sobre os artistas oitocentistas foi escrita nas décadas de 1940/1970, constituindo, ainda hoje, uma das principais fontes para aqueles que procuram referências biográficas sobre estes artistas. No entanto, tais referências, tomadas muitas vezes como "verdades absolutas", denotam uma total ausência de pesquisa a fontes documentais (obras pictóricas e escritos), sendo em sua grande parte errôneas, completamente infundadas, muitas delas verdadeiros "achismos". Torna-se evidente, na nossa compreensão, ser necessário partir, - para termos uma biografia dos artistas oitocentistas que não esteja distorcida por enganos e achismos -, de uma abordagem metodológica que siga os seguintes passos: _ Levantamento da fortuna crítica sobre o artista, e análise crítica da mesma, levando em conta o período em que foram realizadas. _ Levantamento e análise minucioso das fontes primárias (cartas, documentos, e outros escritos) do artista e sobre o artista. _ Levantamento e análise das obras pictóricas realizadas pelo artista no período estudado. _ Levantamento e análise dos textos jornalísticos contemporâneos ao artista e posteriores ao seu falecimento.Por fim, acreditamos que a comparação entre estes levantamentos pode nos levar a descobertas interessantes, que desmistificam os artistas, revelando à luz de documentos e obras que muito do acreditamos terem eles sido e terem eles feito, na verdade não passam de simples construções históricas.

Palavras-chave: Biografia de Artistas Oitocentistas, Arte no Brasil no séc. XIX, Metodologia de Pesquisa.

A presente comunicação tem como objetivo propor uma reflexão crítica a respeito das metodologias utilizadas na produção historiográfica da arte, contemplando uma questão que, apesar de sua grande importância, tem sido muito pouco pensada pelos estudiosos da arte brasileira: a ausência de métodos de pesquisa criteriosos na realização da biografia de artistas brasileiros atuantes no século XIX.

A idéia de refletir sobre tal assunto surge da constatação de que grande parte das referências que encontramos sobre os artistas oitocentistas fornece informações errôneas a seus respeitos. O mais grave é que muitas delas, completamente infundadas, se repetem constantemente na bibliografia mais recente sobre pintores e escultores, - e de um modo geral, em trabalhos sobre arte oitocentista -, sendo estas, muitas vezes, tomadas como "verdades absolutas". Basta, no entanto, uma pesquisa atenta a documentos e obras contemporâneas aos artistas, para que se desfaçam muitos dos enganos históricos construídos sobre eles. Entendemos que tal postura é fundamental para melhor compreendermos não somente suas produções pictóricas, mas também o meio artístico

\footnotetext{
${ }^{1}$ Mestranda em História da Arte pelo Pós-Graduação em História do IFCH/UNICAMP.
} 
brasileiro de fins do século XIX, e mais especificamente o fluminense, com o qual eles estiveram profundamente vinculados.

Pudemos constatar que os livros possuidores de referenciais biográficas sobre os artistas oitocentistas foram escritos, na sua quase totalidade, nas décadas de 1970 e 1980, e prosseguem servindo como base, ainda hoje, para aqueles que procuram dados sobre esses artistas. No entanto, tais referências são utilizadas sem se levar em conta o contexto da historiografia $\mathrm{da}$ arte especifico em que foram realizados, contexto este que determina muitos dos posicionamentos tomados pelos autores que os escreveram. Uma postura crítica quando da leitura destes textos, no entanto, seria suficiente para percebermos que algumas considerações dos autores são infundadas, não estando pautadas em documentação, ou simplesmente sendo definidas por opiniões pessoais a respeito das obras e das trajetórias dos artistas, opiniões estas carregadas, muitas vezes, da dicotomia característica em que esteve mergulhada, de modo geral, a historiografia da arte brasileira até bem recentemente.

Construída a partir do modernismo, esta historiografia procurava apaixonadamente revalorizar o período colonial - "celebrado como as verdadeiras raízes do caráter nacional, que a arte moderna procurava reencontrar - ao lado da rejeição radical ao século XIX, encarado genericamente como acadêmico e alienado - marcado pelo "afrancesamento" da cultura brasileira, uma época de "pastiches" ${ }^{2}$. Diante desse quadro, não excepcionalmente, os autores procuraram valorizar aquilo que servia como marco de origem e evolução das vanguardas, relegando todo resto a um "pacote comodamente etiquetado como acadêmico". A homogeneização do conceito de acadêmico é, de fato, uma limitação que implica na total desconsideração de dados para lá de relevantes na biografia de vários artistas do nosso XIX. Toda a literatura tradicional sobre os artistas oitocentistas vinculados a Academia Imperial de Belas Artes, com algumas pouquíssimas exceções, fixava-se num ponto comum: a apresentação de toda a sua atuação e de toda a sua produção com o rótulo genérico de acadêmico. Esta generalização envolve, na nossa opinião, dois problemas importantes.

O primeiro diz respeito à ausência, nesta literatura, salvo poucas exceções, de uma diferenciação clara entre academicismo e os diversos movimentos artísticos que transpassam, muitas vezes concomitantemente, a obra dos artistas oitocentistas. Sobre o conceito de acadêmico Sonia Gomes Pereira, acertadamente traça a seguinte consideração: Acadêmico é certamente um sistema de ensino ou de produção, é também uma postura do artista diante de sua obra, mas não é propriamente um estilo. Ao se designar, por exemplo, toda a produção da Academia no século XIX simplesmente como acadêmica, deixou-se de efetivamente analisar estas obras, tentando perscrutar nelas a consonância com os estilos da época - o neoclassismo, o romantismo, o realismo, o impressionismo, o simbolismo - sendo inclusive freqüente uma perigosa e errônea identificação entre as denominações acadêmico e neoclássico, ignorando o processo de academização dos demais movimentos ${ }^{3}$.

O outro problema diz respeito a uma tendência na nossa historiografia de pensar "arte acadêmica" como sinônimo de uma "arte retrograda". José Roberto Teixeira Leite e

\footnotetext{
2 PEREIRA, Sonia Gomes. "Academia Imperial de Belas Artes do Rio de Janeiro: revisão historiográfica e estado da questão.”. In: Revista Arte \& Ensaios. Rio de Janeiro: Programa de pós-graduação da Escola de Belas Artes/UFRJ, n. 8, 2001. p. 73.

3 PEREIRA, Sonia Gomes. A Escola de Belas Artes do Rio de Janeiro: Ensino Artístico e Arte Brasileira nos Séculos XIX e XX. Texto não publicado.
} 
Mario Barata, por exemplo, desconsideram a produção artística do pintor Henrique Bernardelli quando do seu retorno ao Brasil, apos de uma estadia de 10 anos na Europa, uma vez que, segundo eles, o artista teria perdido um certo "modernismo" presente em obras como Tarantella, se vinculado à arte oficial, e, portanto, acadêmica". Tal postura é sentida na fala de Mario Barata sobre o artista, em um texto por ele escrito em 1979, no Catálogo Henrique Bernardelli - uma coleção de desenhos:

A evolução desse pintor, naquela arte [do desenho], seu encaminhamento, na maturidade, para uma liberdade de traço e uma segura experiência de relacionamento das formas [...], mesmo se inserido em uma fase acadêmica da arte brasileira [contribuem para] valorizar o trabalho do artista, independente das limitações que este pudesse ter no domínio do exercício da cor a óleo, na qual não obteve a qualidade de um Visconti, no Brasil $[\ldots]^{5}$.

Henrique Bernardelli, no período a que Barata se refere, era professor da ENBA, e estava bastante envolvido com uma produção oficial para o regime republicano. $O$ papel desempenhado pela Escola Nacional de Belas Artes, assim como o de seus professores, no entanto, foi completamente desconsiderado, graças ao notório anti-academicismo que vigorou até bem pouco tempo na cena artística brasileira. Popularizado já desde fins do século XIX, sobretudo na fala dos críticos de arte, esse anti-academicismo associou à ENBA da $1^{\text {a }}$ República a imagem de uma instituição anacrônica, avessa a quaisquer inovações estéticas e alienada da realidade brasileira. Postura esta lamentável, uma vez que nos impede de compreender devidamente um período de nossa arte marcado por importantes transformações. No âmbito artístico, as primeiras décadas do período republicano foram caracterizadas por uma grande vitalidade, o que resultou em um progressivo alargamento dos horizontes estéticos e das estruturas do sistema institucional da arte no Brasil, fato que trouxe conseqüências positivas não só no que diz respeito à diversidade, mas também à qualidade da produção do período. O sistema acadêmico carioca - funcionando então com desenvoltura sem precedentes em sua história, graças à superação de algumas deficiências estruturais crônicas da antiga $\mathrm{AIBA}^{6}$-, foi nada menos do que o principal promotor de tal situação ${ }^{7}$.

O destaque que se dá à arte francesa do período, e o preconceito à alguns gêneros artísticos também contribuem enormemente para uma compreensão errônea da trajetória artística de muito pintores, quando, em muitos casos, não faz mesmo com que alguns caiam no esquecimento. Em alguns textos que tratam especificamente dos artistas de fins do oitocentos, como no "Arte no Brasil no século XIX", publicado em 1999, Henrique Bernardelli, artista de formação italiana, fica completamente eclipsado, se comparado a outros artistas de sua geração de formação francesa, como Rodolfo Amoedo.

\footnotetext{
${ }^{4}$ LEITE, José Roberto Teixeira. "Belle Époque no Brasil”. In: Arte no Brasil. São Paulo: Abril Cultural, 1979. 2 v. BARATA. Mario. Henrique Bernardelli - Uma coleção de desenhos. São Paulo: Pinacoteca do Estado, 1976.

${ }^{5}$ BARATA, Mario.Op. cit.

6 Sonia Gomes Pereira sita as seguintes deficiências: " dificuldades de recursos para a contratação de professores, para a aquisição do material de apoio às aulas, para a manutenção da regularidade dos prêmios de viagem e das exposições gerais; dificuldades de espaço, dada a exigüidade do prédio da Academia; e dificuldade com o nível dos alunos, a maioria pobre e com pouca instrução" PEREIRA, Sônia Gomes. “Academia Imperial de Belas Artes no Rio de Janeiro: revisão historiográfica e estado da questão". In: Revista Arte \& Ensaios. Rio de Janeiro: Programa de Pós-Graduação da Escola de Belas Artes/UFRJ, no 8, 2001, p.75.

7 Sobre o papel da Escola Nacional de Belas Artes, ver: VALLE, Arthur Gomes. "O ensino de pintura na ENBA da $1^{a}$ República”. In: Catálogo do Museu Dom João VI. 2006
} 
Cabe aqui citarmos o exemplo de Teixeira Leite, no seu texto Belle Èpoque no Brasil, período por ele situado "entre 1889, data da proclamação da republica, e 1922, ano da realização da Semana de Arte Moderna de São Paulo, sendo precedida por um curto prelúdio - a década de 1880". Segundo o crítico, seria impossível compreender este período da arte no Brasil fora de suas vinculações com a França. Tal afirmativa é questionável, quando pensamos no fato de que vários artistas de relevo no cenário artístico carioca, entre 1880 e 1900 completaram seus estudos na Itália, - como os Bernardelli, Antonio Parreiras, Belmiro de Almeida, Weingartner, Rafael Frederico, Bento Barbosa, Correa Lima, dentre outros - , tendo lá entrado em contato com os movimentos artísticos considerados pelo crítico como de maior relevo: o Simbolismo e o Art Nouveau. A Itália, portanto, pode ser pensada como uma das "portas" que possibilitavam os artistas brasileiros entrar em contato com as últimas tendências da arte no panorama internacional.

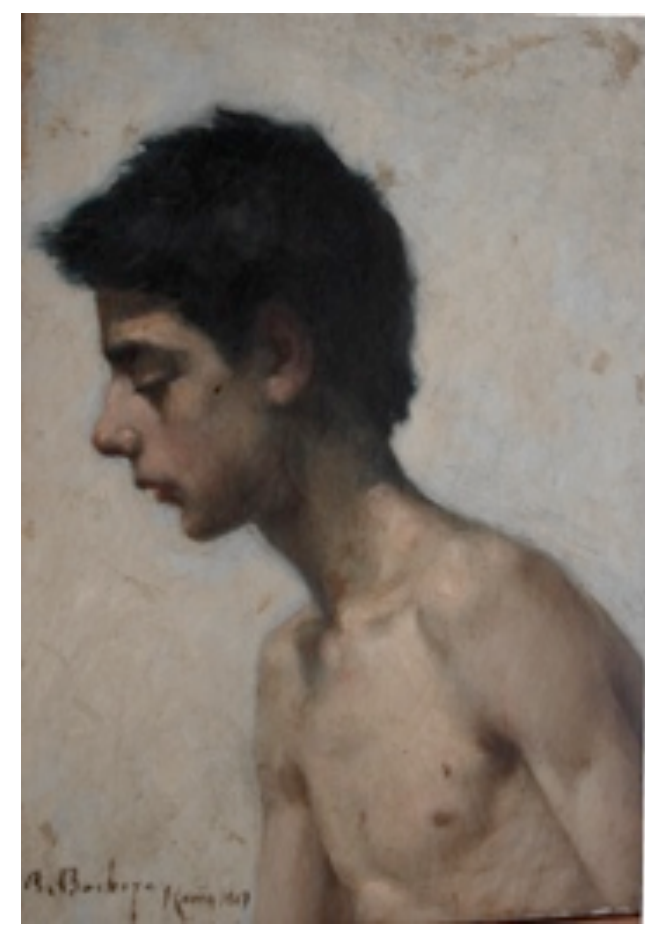

\section{Bento Barbosa \\ Busto de menino, \\ Realizado na Itália, 1897 \\ Acervo do Museu Dom João VI/EBA/UFRJ \\ (foto de Arthur Gomes Valle)}

Apesar desta constatação, são as relações com a França que, ainda hoje, continuam a merecer maior destaque. Reis Junior, no seu livro sobre Belmiro de Almeida, datado de 1984, apesar de fazer referencia ao fato do artista ter estudado na Itália entre aproximadamente 1888 e 1892, considera que as obras do período em que Belmiro se encontra naquele país são 'manifestos do Impressionismo francês':

Historicamente, portanto, a primeira pintura impressionista de Belmiro,impressionista até no título,é de 1892 e executada na Itália: "Efeitos de Sol". O que nos indica não ter o artista procedido levianamente ao filiar-se ao impressionismo; ao contrário, foi uma decisão ruminada pelo menos durante os anos de 1888 a 1892. E quernos parecer que condicionou seu regresso ao Brasil a essa sua tomada de posição, pois só depois dos trabalhos realizados na Itália,nos quais ela está definida, é que Belmiro resolve voltar.

Assim, o Brasil tomava conhecimento dessa inovação quase simultaneamente com seu aparecimento na França, pois em 1894 exibia na Exposição Geral de Belas Artes 
pinturas realizadas nessa técnica. O conjunto exposto mostrava que assimilara o objetivo precipuo do Impressionismo - surpreender a vida - e também suas posteriores pesquisas técnicas para captar a realidade nas suas cambiantes atmosféricas ${ }^{8}$.

Contrariando este escritor, a abertura em direção as novidades que ocorriam no âmbito da arte italiana é claramente percebida nas pinturas deste artista, basta aqui citarmos o já mencionado quadro Efeitos do Sol (1892), cuja técnica empregada é àquela do Divisionismo", tão em voga na Itália daqueles anos, sobretudo na obra de artistas como Giovani Segantini, Angelo Morbelli e Giuseppe Pellizza da Volpedo.

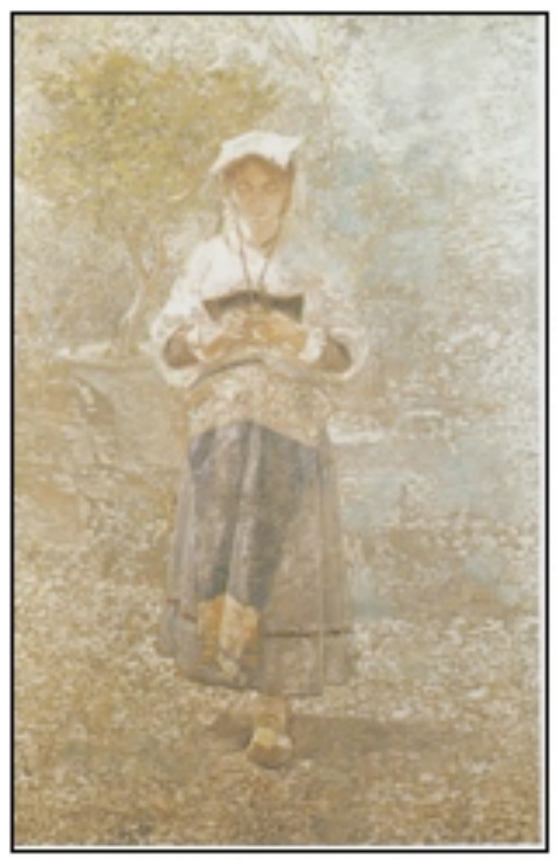

\section{Belmiro de Almeida Efeitos do Sol, Realizado na Itália, 1892 Óleo sobre tela, $100 \times 65$ Acervo Museu Nacional de Belas Artes/RJ}

Outro posicionamento que levou muitos historiadores a desconsiderarem obras, e contribuiu enormemente para muitos enganos e falhas na biografia dos artistas, foi o preconceito à alguns "gêneros artísticos", - como o realismo -, e o enaltecimento de outros, como o Impressionismo e o Simbolismo. No já mencionado texto de Teixeira Leite no livro Arte no Brasil ${ }^{10}$, a obra de muitos deles, como Amoedo, Belmiro e Almeida Jr, se encaixaria na categoria designada pelo estudioso como Realismo Burguês, que é depreciada quando comparado a outros gêneros. Segundo ele:

O Realismo Burguês, que se opunha ao Realismo Popular de Courbet, e se mantinha a margem da renovação pictórica refletindo as predileções artísticas da burguesia [...] Comparado as tendências artísticas que o antecederam, é um retrocesso [...]E, embora alguns de nossos artistas a ele filiados fossem pintores de talento, o fato é que o Realismo Burgues, como um todo, revelou-se formalmente vazio, com seu apelo barato ao sentimental e ao erótico, não raro caindo na mera anedota.

\footnotetext{
${ }^{8}$ REIS JUNIOR, José Maria dos. Belmiro de Almeida 1858-1935. Rio de Janeiro: Pinakotheke, 1984. p. 35.

${ }^{9}$ Para uma rápida definição do Divisionismo italiano, ver o site:

http://www.homolaicus.com/arte/pellizza/divisionismo.htm

${ }^{10}$ LEITE et alii, José Roberto Teixeira. Arte no Brasil, 2 v, Abril Cultural, São Paulo, 1979.
} 
Diante deste posicionamento, fica evidente que somente os artistas filiados, ou que se acreditavam estar filiados, ao impressionismo mereciam ser enaltecidos. Os mais valorizados eram, e continuam a ser, aqueles ligados ao chamado Grupo Grimm - como Antônio Parreiras e principalmente Giovanni Castagneto -, cômodos "equivalentes" brasileiros dos impressionistas franceses, devido a sua prática da pintura de paisagem pleinair, e de maneira análoga, apenas aspectos parciais da obra de outros artistas, como Elyseu Visconti”"11.

Não é difícil identificar que os trabalhos mais recentes sobre os artistas oitocentistas se guiam na fala dos estudiosos anteriormente mencionados, cometendo, inclusive, os mesmos erros de datação. Um deles, bastante decorrente, é situar o retorno de Henrique Bernardelli ao Brasil, após sua estadia na Itália, como tendo ocorrido em 1886, mesmo ano em que se realizava uma exposição de suas obras na sala da Imprensa Nacional ${ }^{12}$. Ao se pautarem em textos escritos durante o século XX, pesquisadores, em livros bastante atuais, repetem essa falha, como é possível verificar no recém publicado Catalogo do $M N B A$, de $2002^{13}$, sendo o mesmo engano corroborado em sites, sempre muito pesquisados, como o ArteData, do historiador da arte Carlos Maciel Levy ou a Enciclopédia do ItauCultural ${ }^{14}$. Nas nossas pesquisas as fontes primárias (documentos, cartas, críticas de arte e outros escritos), pertencentes aos acervos do MNBA/RJ e M. Dom João VI/EBA/RJ, pudemos verificar que Henrique Bernardelli não esteve no Brasil em 1886, tendo retornado somente em 1888, como atesta O Jornal Cidade do Rio, n. 280, ano III, de 07/12/1888, em uma nota anunciando a chegada do artista ao Brasil ${ }^{15}$.

Outro engano freqüente encontrado na fortuna crítica sobre o artista é a tradição de colocar Messalina como tendo feito parte da mostra de 1886. No entanto, o nome de Messalina não consta no catálogo da Exposição, distribuído em sua inauguração, em 31 de outubro daquele ano. Algumas obras que seguramente constaram na exposição também não tiveram seus nomes incluídos no catálogo, - como é o caso de Mater-, o que se explica pelo fato destas terem sido enviadas da Itália, por Henrique, após a exposição ter tido

\footnotetext{
11 VALLE, Arthur Gomes. Op. cit.

12 Em 1886, Henrique Bernardelli, que se encontrava na Itália, envia para o irmão Rodolfo uma série de quadros, que figuraram em uma exposição organizada por este último, na Imprensa Nacional. No mesmo espaço, embora não na mesma sala, foram expostas obras de Nicolao Fachinetti.

13 Quiríno Carnpofioiito cita como expostos os trabalhos, "Mater, Ao Meio-Dia, Messalina,Volta ao Trabalho, Modelo em Repouso (também conhecido por Meditando),e duas cabeças de camponeses italianos". CAMPOFIORITO, Quirino. "Biografias". In: História da Pintura Brasileira no Século XIX. Rio de Janeiro: Pinakotheke, 1983. p, 194.

${ }^{14}$ Nos referidos sites, constam as seguintes notas sobre o retorno do artista em 1886: "Regressando ao Brasil em 1886, Henrique realizou no Rio de Janeiro uma exposição em que apresentou, entre outras muitas obras, Tarantela, Maternidade, Messalina, Modelo em Repouso e Ao Meio Dia”. Retirado do sit: http://www.pitoresco.com/laudelino/bernard/bernardeli.htm. "De volta ao Brasil, em 1886, realiza a primeira individual, na Academia Imperial, expondo Tarantela, Maternidade e Messalina, entre outras”. Retirado do site: www.itaucultural.org.br/

15 Sobre a recepção dos críticos de arte a Exposição de Henrique Bernardelli, realizada em 1886, ver: DAZZI, Camila. A recepção do meio artístico carioca à exposição de Henrique Bernardelli de 1886 - apreciação da imprensa. In: Anais do I Encontro de História da Arte do IFCH Unicamp, Ed. do IFCH, 2006. DAZZI, Camila. "As relações Brasil- Itália no segundo oitocentos: a recepção da crítica de arte carioca à obra dos pintores brasileiros na Itália (1880-1890)". Trabalho apresentado no Seminário Crítica da Crítica. São Paulo: Escola de Comunicações e Artes da USP, Realização: Associação Brasileira de Críticos de Arte, agosto 2005. Texto disponível no site:

http://geocities.yahoo.com.br/dezenovevinte/
} 
início $^{16}$. Estas obras, no entanto, são todas elas mencionadas nas críticas que saem na imprensa em 1886, ao contrario de Messalina que em nenhum momento é mencionada. A obra não é citada nem mesmo por Gonzaga Duque no livro Arte Brasileira, de 1888, onde encontramos um longo texto sobre a exposição de 1886.

Também na documentação da antiga Academia Imperial de Belas Artes, correspondente aos anos de 1886 e 1887, em nenhum momento o nome de Messalina é citado $^{17}$, não tendo sido ela, ao contrario de outros quadros, oferecida à venda para a Academia em $1887^{18}$. A obra também não figurará na Exposição Nacional de Belas Artes de $1890^{19}$, onde estavam presentes várias das obras expostas em 1886, como Ao Sol, Mater e Tarantella, assim como as mais recentes realizações do artista, como Os Bandeirantes. Tais dados nos levam a crer que Messalina é uma produção posterior. O quadro, de fato, só será adquirido pela então Escola Nacional de Belas Artes, em novembro de 1892, como podemos verificar através de um oficio transcrito no Livro de Correspondências Enviadas, da Escola Nacional de Belas Artes ${ }^{20}$.

Tal erro de datação é bem menos irrelevante do que aparenta. $O$ fato do artista não ter realizado a obra em 1886, mas sim em aproximadamente 1892, significaria ter sido ela pintada não por um artista ainda em formação na Itália, mas sim por um, já em 1890, respeitável artista e professor da ENBA.

Torna-se evidente, na nossa compreensão, ser necessário partir, - para termos uma biografia dos artistas oitocentistas, que não esteja distorcida por enganos e achismos -, de uma abordagem metodológica que siga os seguintes passos:

- Levantamento da fortuna crítica sobre o artista, e análise crítica da mesma, levando em conta o período em que foram realizadas.

- Levantamento e análise minucioso das fontes primárias (cartas, documentos e outros escritos) do artista e sobre o artista.

- Levantamento e análise das obras pictóricas realizadas pelo artista no período estudado.

- Levantamento e análise dos textos jornalísticos contemporâneos ao artista e posteriores ao seu falecimento.

A partir de tais levantamentos podemos traçar um quadro em que nos possibilita verificar: 1. datas e informações sobre sua trajetória artística e sua vida pessoal (quase sempre indissociáveis)

\footnotetext{
${ }^{16}$ Angelo Agostini menciona o envio de mais quatro obras vindas da Itália, mas não menciona os seus nomes. Revista Illustrada, 6 de novembro de 1886. p. 3. Mas podemos concluir, a partir da leitura de outros periódicos, que as obras foram: Mater, Tarantella, Ao meio dia e Banho Romano.

${ }_{17}$ Durante vários meses pesquisamos a documentações do Museu Dom João VI da EBA/UFRJ, referente aos anos de 1886 e 1887, (Livros das Atas da Congregação, Livros de Correspondências Enviadas, Livros de Correspondências recebidas, Documentos avulsos), e em nenhum momento o nome do quadro aparece em qualquer documento, ao contrario de outras obras que figuraram na Exposição de 1886.

18 Museu D. J. VI/EBA/UFRJ, Notação: 4994. Datação: 18/01/87 a 10/07/87. Parecer dos professores sobre os quadros oferecidos por Rodolfo Bernardelli a AIBA. Os quadros mencionados são: Abril, Mater, Ao sol, Meditando (pastel), Paisagem de Capri, Tarantela, Carroceiro e Banho Romano.

19 ACADEMIA IMPERIAL DE BELAS ARTES. Catálogo da Exposição Geral de Bellas Artes. Rio de Janeiro, Typographia de J. Villeneuve, 1890. p. 4447,53-54.

${ }^{20}$ No oficio, Rodolfo Bernardelli, diretor da instituição, pede ao Governo dinheiro para pagar a aquisição de algumas obras, dentre elas a tela "Massalina" e o pastel "Modelo em repouso" de Henrique Bernardelli. Museu D. J. VI/EBA/UFRJ. Livro de Correspondências Enviadas, da Escola Nacional de Belas Artes, p. 95. Oficio datado de 17 de novembro de 1892. A mesma data da compra aparece no Inventario de 1921, realizado pelo MNBA. (MNBA - pasta 57). ACADEMIA IMPERIAL DE BELAS ARTES. Catalogo da Exposição Geral de Bellas Artes. Rio de Janeiro, Typographia de J. Villeneuve, 1890. p. 4447,53-54. 54.
} 
2. como o artista procurou solucionar as problemáticas pictóricas comuns a sua geração e o que caracteriza sua obra individual.

3. a imagem que se teve do artista ao longo da sua carreira.

4. a imagem do artista na recente historiografia da arte.

Finalizando, acreditamos que a comparação entre estes levantamentos pode nos levar a descobertas interessantes, que desmistificam os artistas, revelando à luz de documentos e obras que muito do acreditamos terem eles sido e terem eles feito, na verdade não passam de simples construções históricas. 